\title{
Management of stable coronary artery disease: from evidence to clinical practice
}

\author{
Riccardo Gerloni, ${ }^{1}$ Luciano Mucci, ${ }^{2}$ Tiziana Ciarambino, ${ }^{3}$ Manuel Ventura, ${ }^{4}$ Valeria Baglio, ${ }^{5}$ Massimiliano Chiuch,${ }^{5}$ \\ Francesca Saladini, ${ }^{6}$ Stefania Dorigoni, ${ }^{7}$ Davide Tizzani, ${ }^{8}$ Paola Gnerre ${ }^{9}$ \\ ${ }^{1}$ Emergency Medicine, Cattinara Hospital, Trieste; ${ }^{2}$ Internal Medicine, Santa Croce Hospital, Fano (PU); ${ }^{3}$ Internal Medicine, \\ Marcianise Hospital, Caserta; ${ }^{4}$ General Medicine, Ospedale degli Infermi, Rivoli (TO); ${ }^{5}$ Medical Clinic, Cattinara Hospital, \\ Trieste; ${ }^{6}$ Department of Cardiology, Camposampiero Hospital, Padova; ${ }^{7}$ Internal Medicine, Santa Chiara Hospital, Trento; \\ ${ }^{8}$ Emergency and Surgery Medicine, Ospedale degli Infermi, Rivoli (TO); ${ }^{9}$ Internal Medicine, San Paolo Hospital, Savona, \\ Italy
}

\begin{abstract}
Ischemic heart disease, the leading cause of death, is extremely diffuse among patients hospitalized in Internal Medicine ward so that Internist should be able to manage correctly this disease. The following review revises the most recent literature and offers a practical clinical guide to be confident on this topic. After having emphasized that clinical overview remains essential, it briefly mentions advantages and limits of different investigations, reminds readers of possible alternative etiopathogeneses of ischemic heart disease (cardiac syndrome X), reports the most appropriate medical therapy, and gives the opportunity to understand appropriateness of specialist strategies such as coronary artery by-pass grafting and percutaneous coronary intervention. Finally, it illustrates a rational and evidence-based follow-up of these patients, considering that only a small part of them should be followed by a Cardiologist. The aim of a correct management of ischemic heart disease remains to reduce mortality and improve the quality of life.
\end{abstract}

\section{Introduction}

Ischemic heart disease (IHD) is diagnosed when a patient presents one or more symptoms, signs or complications from an inadequate blood supply to myocardium. ${ }^{1}$ This is generally caused by obstruction of the coronary arteries for atherosclerosis and it generally manifests itself with angina. ${ }^{2,3}$ Other symptoms, called ischemic equivalents, are known and can be appreciated as breathlessness, sweating, chest discomfort, shoulder pain, palpitations, jaw pain. If one of

Correspondence: Paola Gnerre, Internal Medicine, San Paolo Hospital, via Genova 30, 17100 Savona, Italy.

Tel.: +30.019.8404082.

E-mail: pgnerre@yahoo.it

Key words: Ischemic heart disease; stable coronary artery disease; angina.

Received for publication: 30 June 2016.

Revision received: 10 August 2016.

Accepted for publication: 17 August 2016.

This work is licensed under a Creative Commons Attribution NonCommercial 4.0 License (CC BY-NC 4.0).

CCopyright R. Gerloni et al., 2017

Licensee PAGEPress, Italy

Italian Journal of Medicine 2017; 11:114-133

doi:10.4081/itjm.2017.755 these symptoms appears predictably and reproducibly at a certain level of exertion and it is relieved with rest or nitroglycerine, stable angina is a more appropriate definition. Severity of symptoms is focused on the classification of the Canadian Cardiovascular Society ${ }^{4}$ (Table 1).

Therefore, different phases of coronary heart disease (CHD) are included in IHD with the exception of acute coronary syndrome. Actually, patients with a history of obstructive or non-obstructive coronary artery disease, who have become asymptomatic with treatment and need regular follow-up, belong to this category either. ${ }^{5}$

Narrowing of $70 \%$ or more in at least one main coronary artery has traditionally represented the pathophysiological mechanism underlying stable IHD, causing exercise and stress-related symptoms. However stable IHD is more complex and physiopathology is based on different mechanisms. ${ }^{6}$ Microvascular dysfunction should be considered when a patient with stable angina shows an insignificant coronary angiography. Specific diseases can also provoke microvascular disease, such as hypertrophic cardiomyopathy or aortic stenosis. In these cases, it is more appropriate to define them as secondary coronary microvascular disease. Focal or diffuse spasm of normal or non-obstructive plaque-diseased artery can be appreciated in patients with angina unrelated to certain level of exertion. In this case pain episodes occur usually at night and in the early morning. Nitrates generally re- 
lieve symptoms within minutes and the electrocardiogram (ECG) shows ST elevation. Finally left ventricular dysfunction secondary to prior acute myocardial necrosis is another sort of manifestation of stable IHD.

For all these reasons it is quite difficult to estimate the incidence of IHD because it depends on setting of pathology. The Health Survey for England reported that around $8 \%$ of men and $3 \%$ of women aged between 55 and 64 years currently have or have had angina. This estimate reaches up to $14 \%$ and $8 \%$ respectively if you consider men and women aged between 65 and 74 years. ${ }^{7}$ For the same reason prognosis depends on the characteristics of selected patients. Generally, estimates of annual mortality rates range from 1.2 to $2.4 \%$ with an annual incidence of cardiac death between 0.6 and $1.4 \%{ }^{8-13}$

\section{Clinical overview and the pre-test risk}

A correct clinical overview is based on accurate medical history. Clinician should distinguish typical pain from atypical form. According to a classification of the clinical symptoms we can consider: ${ }^{14}$ i) typical angina if the pain answers to the characteristics listed above: location (retrosternal), quality (oppressive), etiology (exercise or emotional stress), duration (several minutes) and remission (rest or nitrates); ii) atypical angina, differs from typical angina for the absence of precipitating factors. Pain often starts at rest with a low level of intensity. In case it increases slowly, it reaches its peak for a maximum of $15 \mathrm{~min}$ and then it decreases, an underlying vasospasm can be considered. An atypical presentation for location and quality, caused by physical effort, but unresponsive to nitrates, may underlie a microvascular etiology; iii) nonanginal pain, linked to non-cardiac causes.

The Bayesian approach uses clinical estimates of pre-test disease (test PTP: termed pre-probability) along with the diagnostic tests results to generate individualized probabilities of post-test disease. For CHD clinical estimates of pre-test disease are influenced by the prevalence of disease in the studied population, in addition to the clinical characteristics of the patient (age, gender and nature of the symptoms). ${ }^{15}$
The sensitivity and specificity of a test are influenced by the characteristics of the population on which the test is performed, therefore by the PTP.

The new European Society of Cardiology (ESC) Guidelines on chronic $\mathrm{CHD}^{6}$ starts from PTP to draw a correct diagnostic process for patients with stable chest pain. The PTP is calculated by crossing age, gender and patients' symptoms.

Non-invasive tests for CHD have a sensitivity and specificity of around $85 \%$; so we will get less misdiagnosis, avoiding testing on patients with PTP $<15 \%$ (data for healthy people) or PTP $>85 \%$ (data for sick people): in these patients, tests should be performed only for specific and compelling reasons.

ECG exercise testing has low sensitivity (about $50 \%$ ), for which the number of tests with false result is unacceptable in the population with $\mathrm{PTP}>65 \%$. Based on this assumption, ESC guidelines ${ }^{6}$ suggest a flow chart for the diagnostic and therapeutic management of chronic CHD (Figure 1). The flow chart cannot be applied to patients: i) not candidates for coronary angiography (for which there is indication to medical treatment and to possible further diagnostic study); ii) with symptoms compatible with unstable angina (for which it is necessary to refer to the specific guidelines); iii) with typical symptoms and ejection fraction $<50 \%$ (for which there is indication for coronary angiography).

For patients with PTP $<15 \%$ we should consider other non-cardiac chest pain causes and should not perform specific non-invasive stress-tests. Vasospastic angina should be considered and treated.

Patients with PTP between $15 \%$ and $85 \%$ should perform cardiac stress tests, in particularly imaging stress tests. The ECG exercise testing can be evaluated if the PTP is between $15 \%$ and $65 \%$ or other methods are not available.

For patients with PTP $>85 \%$ CHD diagnosis should be clinical and additional tests do not increase the accuracy.

Coronary computed tomography angiography (CCTA) could also be an alternative to stress tests in patients with a low PTP (between 15 and 50\%) ${ }^{16}$ for its high negative predictive value.

Table 1. Severity of angina according to Canadian Cardiovascular Society.

\begin{tabular}{ll}
\hline Class I (no limitation of ordinary activity) & Angina reproduced with strenuous exertion \\
\hline Class II (slight limitation of ordinary activity) & Angina reproduced on walking rapidly \\
\hline Class III (marked limitation of ordinary activity) & Angina reproduced on walking $100-200 \mathrm{~m}$ \\
\hline Class IV (inability of activity) & Angina reproduced for any activity \\
\hline
\end{tabular}




\section{Biochemical tests, non-invasive cardiac and coronary investigations}

Biochemical tests are recommended to identify cardiovascular risk factors and to determine prognosis. Actually hyperglycemia, dyslipidemia, thyroid disorders and kidney dysfunction should be assessed in every patient with suspected coronary artery disease. ${ }^{6,17}$

Troponin seems to have a prognostic value in patients with stable coronary disease. The increased plasma concentrations could be a predictor of future events (myocardial infarction or death), but it has no sufficient independent prognostic value in out-of-hospital patients. ${ }^{18-20}$

Other biomarkers such as natriuretic peptide, Creactive protein or genetic testing show conflicting results to determine prognosis of stable coronary artery disease. ${ }^{21,22}$

\section{Resting electrocardiography}

Resting ECG can show previous myocardial infarction with $\mathrm{Q}$ waves, or abnormal ventricular repolarization pattern. Anyway, a normal resting ECG is not uncommon even in patients with chronic ischemia. ${ }^{17,23}$

The Report of the American College of Cardiology identified a worse prognosis for patients presenting ECG patterns with $\mathrm{Q}$ waves in multiple leads or an $\mathrm{R}$ wave in V1 indicating a posterior infarction, persistent ST-Twave inversions, particularly in leads V1 to V3; left bundle-branch block (LBBB), bifascicular block, secondor third-degree atrioventricular block, ventricular tachyarrhythmia, left ventricular (LV) hypertrophy. ${ }^{17}$

\section{Resting echocardiography}

According to 2006 ESC Guidelines, the role of resting echocardiography is to detect or rule out dis-



Nothing

Non-invasive test

Angiography
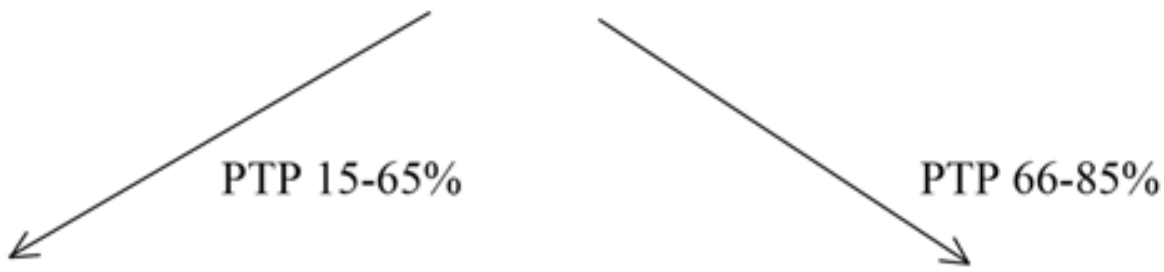

\section{Exercise ECG}

\section{Imaging test}

Figure 1. A correct clinical overview of chest pain. PTP, termed pre-probability; ECG, electrocardiogram. Adapted from Montalescot et al., 2013. ${ }^{6}$ 
orders such as valvular dysfunctions or hypertrophic cardiomyopathy and to evaluate left ventricular function. Moreover, the development of tissue Doppler imaging and strain rate measurements gives the possibility to evaluate diastolic function. ${ }^{24}$ The authors of the most recent ESC guidelines ${ }^{6}$ confirm the indications mentioned above. Echocardiography should be performed in all patients with symptoms of stable coronary artery disease, because identification of LV function stratifies risk ${ }^{6}$ and, particularly, long-term survival. An ejection fraction (EF) $<50 \%$ is recognized to be associated with an annual mortality $>3 \%{ }^{6}{ }^{6}$ These aspects are underlined also in the Canadian and Brazilian Guidelines, ${ }^{4,25}$ where it is emphasized that kinetic alterations can facilitate diagnosis as they can be markers of previous myocardial infarct or ongoing ischemia. Echocardiography can also detect complication of IHD such as ventricle thrombosis in akinetic segments, ventricle remodeling and particularly aneurysmatic deformation, functional mitral regurgitation secondary to myocardial infarction. ${ }^{26}$ In case of insufficient echo quality, microbubble infusion may be a useful adjunct for a better evaluation of wall motion and perfusion, in order to calculate wall motion score index. ${ }^{25,27}$

\section{Coronary computed tomography angiography and calcium scoring}

Patients with a low-intermediate risk of obstructive CHD (15-50\%) can be investigated with CCTA. ${ }^{6,17}$ They should not be obese, without breath holding capabilities; they should be in sinus rhythm with a preferably heart rate of 65-60 b.p.m. ( $\beta$-blockers or others rate-lowering medication can be used before the exam) and with a favorable calcium score (Agatson $<400){ }^{6,17-20}$ All these precautions permit good quality images.

Measurement of calcium scoring is calculated as the product of the coronary artery calcium area by maximal plaque density (in Hounsfield units) and calcified lesions are quantified using Agatson score. Calcium score is useful for risk assessment in asymptomatic individuals, identifying the presence of coronary atherosclerosis, but it poorly correlates with narrowing of the lumen, especially in young individuals with acute symptoms (who can have a coronary artery calcification score of zero) and in patients with Agatson score $>400$ (stenosis can be overestimated) ${ }^{6,17,18}$

\section{Exercise or pharmacological stress echocardiography}

Exercise testing with echocardiography is useful to identify the presence, location and extension of myocardial ischemia, during stress test an appropriate bi- cycle ergometer is used and images are acquired at rest and at each stage of exercise, including peak. Sensitivity and specificity for detection of coronary artery disease range from 53 to $93 \%$ and from 70 to $100 \%$ respectively. ${ }^{1}$ The use of injectable agents is described as valuable for a better identification of myocardial perfusion, while tissue Doppler and strain rate improve the capability to detect ischemia. Tissue Doppler imaging allows regional quantification of myocardial motion (velocity), while strain (difference in velocities between adjacent regions) and strain rate (difference per unit length) allow determination of regional deformation. ${ }^{1}$ In patients unable to perform exercise, pharmacological stress test may be performed. Two different approaches are suggested: ${ }^{24}$ i) infusion of short-acting sympathomimetic drugs such as dobutamine in incremental dose protocol which increases myocardial oxygen consumption similarly to physical exercise; ii) infusion of coronary vasodilator agents (i.e., dipyridamole, adenosine) which provides a contrast between regions supplied by non-pathological coronary arteries (where perfusion increases) and regions supplied by stenotic arteries (where a lower increase or a decrease of perfusion is predictable). ${ }^{24}$ Brazilian Guidelines ${ }^{25}$ report different sensitivity for different stress agent used, in the presence of one-vessel disease: $38 \%$ for dipyridamole, $70 \%$ for exercise stress test, $61 \%$ for dobutamine stress test; the addition of atropine to dobutamine is suggested to improve accuracy and decreases the rate of ineffective test, especially in patients taking $\beta$-blockers. ${ }^{25}$ In contrast to 2006 guidelines, 2013 ESC Guidelines ${ }^{6}$ consider $^{2}$ dobutamine the pharmacological agent of choice to produce supply-demand mismatch and suggest the use of contrast media and microbubbles to assess myocardial perfusion. Their use is considered as mandatory when two or more segments are not well visualized at rest. ${ }^{6}$ Tissue Doppler imaging and strain rate imaging are valuable to improve the diagnostic performance of stress echocardiography to detect ischemia. ${ }^{6}$ Stress imaging compared to exercise ECG test has a superior diagnostic performance (for stress echo sensitivity 80$85 \%$, specificity $80-88 \%$, vs for exercise ECG $40-45 \%$ and $85-90 \%$ respectively), ability to quantify and localize areas of ischemia and to provide diagnostic and prognostic information in patients with ECG abnormalities, particularly in those with previous coronary artery disease. ${ }^{26-28}$

As it is mentioned in 2013 ESC guidelines, physical stress test is preferable to pharmacological one, because the former gives information such as exercise and work load, changes in heart rate and blood pressure. ${ }^{6}$ Regional wall motion abnormalities at rest and inability to perform exercise adequately are the only two situations to prefer pharmacological stress test.

In the American Heart Association (AHA) 2014 
Guideline for the diagnosis and management of patients with stable IHD there is no mention of non-invasive examinations as resting or stress echocardiography. ${ }^{29}$

\section{Cardiac magnetic resonance at rest and stress testing}

Cardiac magnetic resonance (CMR) can be performed at rest or as stress test, using dobutamine infusion (to detect wall motion abnormalities induced by ischemia) or vasodilator agents like adenosine. Moreover, CMR can be useful to assess coronary anatomy (magnetic resonance coronary angiography) ${ }^{6}$

CMR can be useful in the detection of CHD and, particularly, in assessing myocardial viability, detection of small subendocardial infarctions and ventricular function before revascularization, risk stratification in suspected CHD and evaluation of myocardial ischemia. ${ }^{30}$

Main and appropriate recommendations on the use of CMR are: ${ }^{31}$ i) detection of CHD in symptomatic patients: evaluation of chest pain syndrome using vasodilator perfusion CMR or dobutamine stress function CMR and MR coronary angiography; ii) risk assessment of CHD in previous coronary angiography (catheterization or CT) with stenosis of unclear significance, using vasodilator perfusion CMR or dobutamine stress function CMR; iii) detection of myocardial scar and viability, using late Gadolinium enhancement.

\section{Electrocardiogram exercise testing}

Stress ECG is a widespread test, used both for IHD diagnosis and event risk stratification (Duke Treadmill score) $)^{32,33}$ It is performed by treadmill or bicycle exercise, recording a 12-lead ECG.

The exam is diagnostic when recording ECG demonstrates a depression $\geq 0.1 \mathrm{mV}$, persisting for at least $0.06-0.08 \mathrm{~s}$ after the J-point, in one or more ECG leads at peak exercise or during recovering. High risk of mortality is present in patients whose ST-segment depression appears at a reduced workload or persists into recover. Important additional non-ECG factors are exercise duration, chronotropic incompetence, angina, ventricular arrhythmias, heart rate recovery, and hemodynamic response to exercise (i.e., drop in systolic blood pressure), or when combination scores such as the Duke Treadmill or Lauer scores are applied. ${ }^{17}$

The exercise stress test should be stopped for the following reasons: symptoms limitation, combination of symptoms such as pain with significant STchanges; marked ST-depression, ST-elevation $>1 \mathrm{~mm}$, significant arrhythmia, sustained fall in systolic blood pressure $>10 \mathrm{mmHg}$, marked hypertension $(>250$ $\mathrm{mmHg}$ systolic or $>115 \mathrm{mmHg}$ diastolic); achievement of maximum predicted heart rate. Limitations to the correct interpretation of the test are the presence of LBBB, paced rhythm and Wolff Parkinson White (WPW) syndrome, because in these cases ECG changes cannot be evaluated. Additionally, false positive results are more frequent in patients with abnormal resting ECG for left ventricular hypertrophy (LVH), electrolyte imbalance, intraventricular conduction abnormalities and use of digitalis. Antianginal therapy should be stopped for $24-48 \mathrm{~h}$ before test. It is not diagnostic if at least $85 \%$ of maximum heart rate is not achieved. ${ }^{24}$

Exercise stress testing can also be useful to evaluate the efficacy of treatment, to assist prescription of exercise after control of symptoms, to calculate the patient's event risk (using Duke Treadmill score that combines exercise time, ST-deviation and angina). ${ }^{34-37}$

\section{Single-photon emission computed tomography myocardial perfusion imaging, stress perfusion scintigraphy and positron emission tomography}

Myocardial perfusion single-photon emission computed tomography myocardial perfusion imaging (SPECT) is generally performed using Tc-99m or Tl201 and it is conducted by using vasodilator agents (adenosine or regadenoson, dipyridamole) or dobutamine. The major limit is high radiation exposure. Myocardial hypoperfusion is characterized by reduced tracer uptake at rest or after stress. Stress perfusion scintigraphy is usually ECG-gated SPECT that adds additional information about ejection fraction and left ventricular motility. Another important rule of SPECT is to assess myocardial viability, evaluating radionuclides distribution after nitrate administration.

Brindis et al. ${ }^{38}$ defined the following main appropriate criteria of SPECT myocardial perfusion imaging: i) detection of CHD in asymptomatic and symptomatic patients (evaluation of chest pain syndrome) when PTP is intermediate; ii) risk assessment with prior test results: worsening of the symptoms, or follow-up in stable disease; iii) risk assessment with prior test results in unstable angina/non ST-elevation myocardial infarction (NSTEMI), STEMI, pre-operative or post-revascularization [percutaneous coronary intervention (PCI) or coronary artery bypass grafting (CABG)]; iv) risk assessment with prior test results: prior coronary calcium Agatston Score greater than or equal to 400 ; v) assessment of viability/ischemia: ischemic cardiomyopathy (including SPECT imaging for wall motion and ventricular function) in patients eligible for revascularization.

In comparison with SPECT, positron emission tomography (PET) is less available and more expensive. However, it offers a high sensitivity technique in the detection of CHD (in particular microvascular disease), quantifying myocardial blood flow using positron-emitting radiotracers (like ${ }^{82}$ Rubidium or ${ }^{13} \mathrm{~N}$ ammonia). ${ }^{39,40}$ 


\section{Management of stable ischemic heart disease}

Symptoms control, improved survival and prevention of cardiovascular events are the main aims of therapy in patients affected by stable IHD. ${ }^{41,42}$ Optimal management requires risk factors control (such as treatment of hypertension, dyslipidemia and diabetes mellitus, cessation of smoking, weight reduction, stress reduction), regular physical activity and therapies assumption, such as antianginal and antiplatelet drugs. ${ }^{43,44}$

$\beta$-blockers, used as first line therapy, improve exercise tolerance and reduce anginal episodes by limiting oxygen consumption for their inotropic and chronotropic action, and increasing perfusion of ischemic areas for diastole prolongation. Further, they improve survival in patients with stable coronary disease with systolic heart failure or previous myocardial infarction. In contrast, there is not enough evidence that $\beta$-blockers reduce the risk of death in patients with stable coronary heart disease in the absence of recent myocardial infarction or heart failure. ${ }^{45,46} \beta$-blockers may be used in combination with dihydropyridines (DHP) calcium channel blockers, but they should be avoided in combination with non-DHPs, due to the risk of bradycardia or atrioventricular block. ${ }^{6}$ Further, they should not be used in patients with vasospastic or variant (Prinzmetal's) angina, because they may induce coronary vasospasm.

Calcium channel blockers are generally used as second line therapy when $\beta$-blockers cause side effects or are contraindicated. Calcium channel blockers decrease contractility and induce coronary and peripheral vasodilatation, reducing peripheral vascular resistance. ${ }^{47}$ Non-DHPs reduce also the heart rate inhibiting sinus node. Verapamil is used in all varieties of angina - effort, vasospastic, unstable - supraventricular tachycardia and hypertension. DHPs may be used in association with $\beta$-blockers due to greater antianginal effect, even if this combination is often underused. ${ }^{48}$

Nitrates induce coronary arteriolar and venous vasodilatation by means of their active component nitric oxide, so reducing the preload. Nitrates may be shortacting or long acting. Long-acting nitrates are used for angina prophylaxis, but they are not continuously effective if taken over a prolonged period, because they induce tolerance that should be prevented by changes in dosing and timing of administration or using slowrelease preparations. ${ }^{49-51}$

Ranolazine, a late sodium channel blocker, is another antianginal agent without influences on blood pressure and heart rate, used alone or in combination with $\beta$ blockers. ${ }^{52}$ It is used in patients intolerant or non-responders to first-line agents as $\beta$-blockers or calcium antagonists. QTc should be monitored because ranolazine prolongs QT duration. In patients with stable chronic angina, ranolazine reduces recurrent ischemia ${ }^{53}$ and improves $\mathrm{HbA} 1 \mathrm{C}$ in diabetics for a better insulin secretion. ${ }^{54,55}$ Improvement of patients with chronic angina is demonstrated in a series of trials which consider different outcomes such as exercise stress test performance (duration, time to angina, time to ST-segment depression), ${ }^{56-58}$ quality of life, ${ }^{59}$ and frequency of angina with need for nitroglyercin. ${ }^{60-62}$ Ranolazine is well tolerated and its most frequent adverse events reported were dizziness $(11.8 \%)$, constipation $(10.9 \%)$, and peripheral edema $(8.3 \%) .{ }^{63}$ Ranolazine is contraindicated with potent inhibitors of the CYP3A4 pathway including certain antifungals (ketoconazole and other azole class), antibiotics (macrolides, clarithromycin), HIV protease inhibitors, diltiazem, and grapefruit products. ${ }^{64}$

Ivabradine reduces heart rate, inhibiting the sinus node pacemaking current. So, it decreases myocardial oxygen demand without effects on blood pressure and contractility. Its use is approved for therapy of chronic stable angina in patients intolerant to $\beta$-blockers or uncontrolled by the latter, because it reduces heart rate and the number of angina attacks. ${ }^{65}$ It decreases symptoms in patients with stable angina pectoris and improves outcomes in patients with systolic heart failure ${ }^{66-68}$ Ivabradine is shown to reduce disability, by limiting angina episodes and disease perception. As recently demonstrated in a substudy, ${ }^{69}$ this positive drug effect is maintained over 3 years of follow-up and the best improvement is evident for patients in the lowest tertile for angina frequency score at baseline. Statistical analyses also reveal an improvement in physical limitation at 6 months, despite this datum loses its statistical significance on time. However, in this substudy a positive trend on angina-related quality of life emerges for patients treated with ivabradine and this aspect should be kept in mind by Internists who generally deal with very old patients.

Nicorandil is a nitrate derivative of nicotinamide that can be used for the prevention and long-term treatment of angina. This drug dilates epicardial coronary arteries and stimulating ATP-sensitive potassium channels in smooth muscle cells of blood vessels. The prospective study IONA (impact of nicorandil in angina) reported a reduction of cardiovascular events (such as coronary heart disease death, non-fatal myocardial infarction, or unplanned hospitalization for cardiac chest pain) by $14 \%$ in 2565 patients taking Nicorandil (against 2561 patients assessed to placebo) in follow up for an average of 1.6 years (range 1-3 years). ${ }^{70,71}$

Other antianginal drugs, such as allopurinol, molsidomine and trimetazidine, may be used on few evidence of their efficacy. Finally, antiplatelet agents are used in the prevention of vascular events. If there are no contraindications, all patients with stable angina 
pectoris are treated with aspirin. Patients allergic to aspirin can be treated with clopidogrel - antagonist of the platelet ADP receptor P2Y12. ${ }^{72}$ Prasugrel and ticagrelor have not been evaluated in patients with stable angina. Finally, combined antiplatelet therapy is beneficial in patients with stable angina who have undergone elective PCI. Patients with documented CHD have a very high risk of cardiovascular events and receive benefits from statins treatment (LDL-C target of $1.8 \mathrm{mmol} / \mathrm{L}$ or $70 \mathrm{mg} / \mathrm{dL}$ ). ${ }^{73}$ Statins can reduce mortality and the incidence of acute coronary syndromes; in addition, there is increasing evidence that they reduce the incidence of anginal episodes in patients with stable IHD. In the AVERT trial, patients treated with atorvastatin had a reduction in the rate of hospitalization for worsening angina compared to patients treated with angioplasty and without statins. ${ }^{74}$ In the DUAAL trial, patients with stable IHD were randomly assigned to one of three treatments: amlodipine, atorvastatin or amlodipine plus atorvastatin. During 48 hours, patients treated with atorvastatin had a reduction of ischemic episodes and more than 50 percent of patients were asymptomatic at 26 weeks. ${ }^{75}$ The use of ACE inhibitors in stable IHD is controversial; actually clinical trials have not evenly demonstrated that the ACE inhibitors reduce cardiovascular mortality, non-fatal heart attack, stroke and heart failure in patients with atherosclerosis and preserved left ventricular function. ${ }^{76}$ Instead, it is appropriate to use ACE inhibitors in patients with stable angina if hypertension, chronic kidney disease, diabetes or ventricular dysfunction ( $\mathrm{LVEF} \leq 40 \%$ ) coexist. $^{77}$

\section{Invasive treatment of cardiac ischemia: coronary artery bypass grafting or percutaneous coronary intervention?}

In patients with refractory symptoms to medical treatment the choice is revascularization strategy, percutaneous or surgical revascularization. ${ }^{6}$ Therefore $\mathrm{CABG}$ or PCI, may be indicated in flow-limiting coronary stenosis to reduce myocardial ischemia and its adverse clinical manifestations. ${ }^{78-80}$ Subsisting similar goals, revascularization and medical therapy must be considered as complementary.

CABG was performed for the first time in $1964 .{ }^{81}$ The first PCI was introduced thirteen years later. ${ }^{82}$ Both revascularization techniques have improved in the following years: $\mathrm{CABG}$ with the use of arterial conduits, PCI with the advent of stent. ${ }^{83}$

Both the procedures (CABG and $\mathrm{PCI}$ ) present risks that are summarized in Table $2 .{ }^{84}$

Formulation of the best revascularization approach requires interaction among cardiologists, cardiac surgeons and the patient, who should be adequately informed. ${ }^{85}$

The choice among medical therapy, CABG or PCI depends on the risk-benefit ratios of every strategy. Numerous models have been developed for risk stratification, based on anatomical complexity or clinical risk, ${ }^{86}$ such as the EuroSCORE, old and no more used ${ }^{87}$ the EuroSCORE II, ${ }^{88,89}$ the STS score ${ }^{90}$ for CABG surgery, the SYNTAX score, ${ }^{91}$ the NCDR CathPCI risk score, ${ }^{92}$ the ACEF mode ${ }^{93}$ for PCI, the SYNTAX II score ${ }^{94}$ for comparing CABG with PCI, the ASCERT study, ${ }^{95}$ used to predict mortality at different time point following CABG and PCI. ${ }^{96,97} \mathrm{Un}-$ fortunately the variability of these models and the absence of several important variables, such as frailty, physical independence and porcelain aorta, do not permit to identify one specific risk model, universally accepted and validated. Therefore, the risk stratification should be used as a guide, while clinical judgment and multidisciplinary dialogue remain essential. ${ }^{94}$

Several trials compared CABG with PCI, and either CABG and PCI with medical therapy. The best results occurred for PCI with use of the new-generation drug-eluting stents and for $\mathrm{CABG}$ with maximal use of arterial grafts..$^{98}$

The majority of these studies have some limits: i) included only male patients who were relatively young, with preserved left ventricular function and without previous revascularization; ii) the patients were highly selected: they were randomized by delin-

Table 2. Complications of revascularization procedures.

\begin{tabular}{ll}
\hline Coronary artery bypass grafting & Angioplasty \\
\hline Bleeding & Emergency open-chest surgery \\
\hline Stroke & Stroke \\
\hline Heart attack & Heart attack \\
\hline Death & Death \\
\hline Anesthesia problems* & Hematoma \\
\hline Local infections & Coronary dissection \\
\hline
\end{tabular}

*Some people have memory loss and trouble thinking clearly, especially in the elderly, and these problems tend to improve several months after surgery. 
eation of coronary anatomy by angiography, without routine assessment of ischemia; iii) the revascularization was performed when medical therapy failed; iv) the proportion of patients who did not undergo revascularization progressively declined during follow-up, camouflaging differences between the two strategies (CABG and PCI); v) time of follow-up was limited, usually less than five years: so reducing the possible evaluations about the advantages of CABG related to arterial grafts. ${ }^{98}$

Medicines are the primary options for stable, lowrisk CHD, and should be given to all CHD patients. Medically refractory is a useful high-risk marker of potential benefit from revascularization.

The COURAGE trial reported no difference in death, myocardial infarction and stroke with PCI compared with medical therapy for stable angina. On the other hand, patients without angina were significantly more numerous in the PCI group at one and three years. The difference was minor at five years, when patients in both groups underwent additional revascularization (21\% in the PCI group and 33\% in the medical therapy group respectively). ${ }^{99}$ Most of other meta-analyses do not describe differences between PCI and medical treatment in terms of death, myocardial infarction, unplanned revascularization or angina. ${ }^{100-103}$

The results in terms of rates of death, cardiac death and non-fatal myocardial infarction are similar if comparing early generation drug-eluting stents versus baremetal stents, while a relative risk reduction in the need for subsequent or repeat target vessel revascularization was registered with the use of drug-eluting stents. ${ }^{103,104}$

Compared with bare-metal stents and early generation drug-eluting stents, new-generation drugeluting stents have also improved safety outcomes including death, myocardial infarction and stent thrombosis. ${ }^{103,105-108}$

The superiority of $\mathrm{CABG}$ with internal mammary artery to medical therapy for specific subset of CHD resulted into two meta-analyses that demonstrated survival benefit in patients with left main or three-vessel CHD, particularly when the proximal left anterior descending coronary artery was involved. Benefits were greater in patients with severe symptoms, early positive exercise tests and impaired left ventricular function. ${ }^{109,110}$

It is very difficult to choose between the two revascularization strategies (CABG or PCI), because neither $\mathrm{PCI}$ nor $\mathrm{CABG}$ alone can provide a solution for the entire spectrum of $\mathrm{CHD}$ patients who need revascularization. $\mathrm{CABG}$ permits more complete revascularization than PCI, especially with chronic proximal occlusions. ${ }^{88}$

The choice of the most appropriate strategy of myocardial revascularization remains debatable in many patients. Randomized trials comparing surgery (CABG) to angioplasty (PTCA) have shown that both modalities are equivalent in terms of survival or infarct free survival. In patients with type 2 diabetes mellitus in the BARI 2D Trial, a strategy of revascularization with $\mathrm{CABG}$ or $\mathrm{PCI}$ resulted in no difference in mortality compared with optimal medical therapy, ${ }^{111}$ but patients treated with PTCA required many more admissions for additional revascularization procedures during follow up, with increasing of the time away from a normal active life, and increasing costs in the treatment of proximal left anterior descending coronary artery disease ${ }^{112,113}$ and left main coronary artery disease (in this case some trials demonstrated more risk of stroke in the group treated with CABG). ${ }^{114,115}$ In case of three-vessel coronary artery disease, the studies are discordant: a meta-analysis including patients treated before the use of drug-eluting stents demonstrated no differences between PCI and CABG in terms of mortality in all patients, but with reduced mortality in diabetics and in aged 65 years or more patients if treated with CABG. ${ }^{116}$ A following metaanalysis with patients treated with drug-eluting stents reported a significant reduction in mortality, myocardial infarction and repeat revascularization in those groups performed with $\mathrm{CABG}$, but with increasing risk of stroke. ${ }^{117}$ There is notable consistency in the findings on the survival advantage of CABG over PCI for more severe three-vessel CHD. ${ }^{98}$

The decision to treat patients with CABG has been largely based on CHD extension and left ventricular function. Considering patients with stable and unstable angina (excluding recent myocardial infarction), those with left main narrowing $>50 \%$ or three-vessel stenoses $>70 \%$, or even two-vessel stenoses $>70 \%$, where one of the vessels is the proximal left anterior descending, presented minor mortality if treated with CABG. ${ }^{118}$

Specific advantages of CABG include: revascularization of chronically occluded vessels with collaterals supplying viable myocardium, protection of territories rather than simply treating lesions, greater durability of conduits compared to bare-metal stents, while in this case the difference with drug-eluting stents is poor. Based on these principles, physiologic rather than anatomic considerations are most useful in determining whether and how urgently to revascularize: STEMI is an emergent indication and high-risk nonSTEMI an urgent indication. Coronary anatomy, including both number of vessels and lesion characteristics, continues to influence decision on reperfusion strategy and patient specific strategies. ${ }^{119}$

The majority of the PCI versus CABG trials enrolled populations that were at relatively low risk for ischemic clinical events. Trials demonstrated few hard outcome (survival, MI, or stroke) differences between CABG and PCI. CABG continues to be the most suitable revascularization option for patients with multi- 
vessel, multi-lesion CHD, PCI is the acute stabilization method of choice for patients with on-going ischemia and acute MI, especially among patients with hemodynamic compromise, and/or major comorbidity. Bypass surgery remains the treatment of choice in diabetics only in case of complex coronary anatomy such as multi-vessel CHD, left main CHD and in patients with multi-vessel disease and impaired ventricles. ${ }^{119}$

\section{Cardiac syndrome $\mathrm{X}$ : angina pectoris with normal coronary arteries}

Cardiac syndrome $\mathrm{X}$ is a clinical syndrome that refers to patients with angina and normal coronary artery, who can show evidence of coronary microvascular dysfunction or abnormalities on stress testing. Microvascular dysfunction causing ischemia is due to endothelial cell dysfunction, abnormal cardiac adrenergic tone and occult small vessel coronary artery disease. The cardiac microvasculature may have a reduced vasodilator, or even a paradoxical vasoconstrictor response to several pharmacologic agents and exercise. ${ }^{120}$ Because of these abnormalities, cardiac syndrome $\mathrm{X}$ has also been called microvascular angina. Increased cardiac sympathetic tone ${ }^{121}$ and increased response to $\beta$-adrenergic stimulation ${ }^{122}$ can contribute to autonomic system abnormalities. Actually, enhanced sensitivity to intracardiac pain or the so-called sensitive heart syndrome may result from sympathovagal imbalance with sympathetic predominance ${ }^{123}$ or reduced activity of the endogenous opioid system. ${ }^{124}$

Patients with cardiac syndrome $\mathrm{X}$ are younger than those with atherosclerotic cardiovascular disease and predominantly female. ${ }^{125}$ In fact, myocardial ischemia and/or coronary microvascular dysfunction is present in 20 to 50 percent of women with chest pain and normal coronary arteries. ${ }^{126}$ Patient with cardiac syndrome $\mathrm{X}$ may have an acute coronary syndrome due to a ruptured atheromatous plaque and no residual lesions greater than 50 percent. ${ }^{127}$ Normal coronary anatomy or vessels without $\geq 50$ percent stenosis have been reported in $9-14 \%$ of patients with a non-ST elevation ACS. ${ }^{128}$

\section{Management}

Considering patients with cardiac syndrome $\mathrm{X}$, the chest pain is similar to classic angina pectoris in about one-half of them. It may be precipitated by effort, but also occurs at rest. ${ }^{129}$ However, compared to no intervention, exercise training improved exercise capacity by 34 percent and delayed the onset of pain during exercise by 100 percent, although the maximum pain was unchanged. ${ }^{130}$
The episodes are predominantly exertional, frequently occur from midnight to early morning and each episode generally lasts 5 to $15 \mathrm{~min}$. Many undiagnosed patients with anginal type chest pain relieve symptoms with sublingual nitroglycerin. ${ }^{131}$ Tachycardia, hypertension, diaphoresis, and a gallop rhythm can be noticed when symptoms are present.

A 12-lead ECG should be performed in all patients with a history of chest pain. The ECG is usually normal between episodes. Transient ECG changes, with ST segment depression are common. ${ }^{132}$ The absence of ECG changes does not exclude a cardiac etiology. ST-segment elevation, that is the hallmark of variant (Prinzmetal's) angina, is not a feature of cardiac syndrome X. ${ }^{133}$ Ambulatory ECG monitoring for $24 \mathrm{~h}$ may be helpful for documenting ST segment changes.

The typical finding on the exercise ECG is horizontal or down-sloping ST segment depression. Exercise thallium-201 myocardial scintigraphy may demonstrate regional myocardial perfusion defects during exercise. ${ }^{134}$ Studies have demonstrated neither perfusion defects nor regional wall motion abnormalities after dobutamine or transesophageal atrial pacing, ${ }^{135}$ because the ischemia is limited to the subendocardium. ${ }^{136}$

A coronary angiogram showing normal epicardial coronary arteries ( $<30$ percent diameter reduction) is necessary to diagnose cardiac syndrome $\mathrm{X}$. Lesions between 30 and 50 percent may be evaluated with either fractional flow reserve or intravascular ultrasound. ${ }^{137}$

Measurement of coronary flow reserve (CFR) can show microvascular disease ${ }^{138} \mathrm{CFR}$ is the ratio of maximal hyperemic coronary blood flow, measured after infusion of a coronary vasodilator such as adenosine or dipyridamole, to resting or basal coronary blood flow. Normal CFR ranges from 2.5 to 5 . Occasionally it is greater than 5. Maximal coronary blood flow should be at least 2.5 times the resting blood flow. CMR can be useful for studying patients with a possible diagnosis of cardiac syndrome $\mathrm{X}$ and it is able to detect regional differences in myocardial blood flow. ${ }^{139}$

$\mathrm{LVH}$, right ventricular hypertrophy, stress induced cardiomyopathy, systemic amyloidosis ${ }^{140}$ should be considered and exclude before diagnosing syndrome $\mathrm{X}$.

Patients with cardiac syndrome $\mathrm{X}$ and stable angina generally have an excellent prognosis, while those with acute coronary syndromes have an appreciable acute mortality. ${ }^{141}$

All patients with cardiac syndrome X should be treated with aggressive risk factor reduction and sublingual nitroglycerin.

The 2013 ESC guidelines on the management of stable coronary heart disease recommend that all patients receive secondary prevention medications including aspirin and statins and that $\beta$ blockers should 
be used as first line therapy. ${ }^{6}$ Calcium channel blockers are used if $\beta$-blockers are not effective. Statins have been shown to improve coronary artery endothelial function ${ }^{142}$ and $\beta$-blockers are most effective in reducing the frequency and severity of angina and in improving exercise tolerance. ${ }^{143}$ Atenolol significantly reduces anginal episodes and improves quality-of-life measures.

Ranolazine is a novel anti-anginal agent and it resulted in significantly improved myocardial perfusion. ${ }^{144}$

Hormone replacement therapy may be beneficial in some postmenopausal women with chest pain and estrogen deficiency. Estrogen may act by improving endothelium-dependent coronary vasomotion. ${ }^{145}$

Ace-inhibitors, imipramine and L-arginine and spinal cord stimulation have a secondary role in patients who persist symptomatic. ${ }^{146}$

\section{Follow up of patient with stable ischemic heart disease}

The management of stable IHD aims to relieve symptoms, to improve the quality of life and to reduce the risk of acute coronary syndrome, heart failure and death.

The literature has shown that a periodic follow-up of these patients reduces the individual cardiovascular risk and increases the quality of life. ${ }^{147}$ However, no randomized trials assess the prognostic impact of different follow-up strategies, ${ }^{6}$ therefore most of the guidance provided by the international literature and the scientific community are based on expert opinion or on small retrospective studies or registries.

Guidelines recommend clinical evaluations every four to six months in the first year after the ischemic event. After the first year, in patients with stable conditions, even in patients with important systolic dysfunction, the follow-up can be performed every 6 to 12 months, if the patient is enough reliable to call for an appointment in case symptoms or functional capacity become worse. This follow-up should be performed by a general practitioner, with possible reference to a cardiologist in cases of doubts and uncertainties. ${ }^{6,17}$

Additional prospective studies are required to establish appropriate follow up strategies and efficient time intervals for evaluation. There is not yet a prognostic score for detection of patients with stable IHD who are at high risk of major adverse cardiac events. Surely adverse outcomes are associated with time to ischemia during exercise, frequency and severity of angina, onset of recurrent symptoms $<6$ months, prior infarction or CABG, resting ECG abnormalities, $\mathrm{LVH}$ or enlargement or abnormal function, coronary angiography stenosis, diabetes mellitus, comorbidities, age, smoking and sex. ${ }^{17,148-150}$
The guidelines do not define precisely the elements needed in follow-up visits. In general terms, the literature suggests careful interval medical history evaluation, limitations in physical activity, assessment of symptoms and clinical and functional status, physical examination (including measurement of weight and waist circumference and BMI, as well as blood pressure and heart rate), and execution of first level laboratory exams according to patient's clinical evaluation. ${ }^{6,17,147,151}$

Medical examination should consider adherence to drug and behavioral therapy, onset of adverse effects, monitoring of cardiovascular risk factors and comorbidities, recurrence of ischemia, onset of symptoms and signs suggestive of heart failure, arrhythmias, heart valve disease and peripheral vascular disease. The American guidelines suggest SAQ (Seattle angina questionnaire, a 19-item, self-reported questionnaire validated to quantify the symptoms, functional limitations and quality of life of patients with stable IHD) as a tool for monitoring the patient's clinical status. ${ }^{17}$

Glucose, creatinine, lipid profile and glycated hemoglobin in diabetic patients should be periodically evaluated. Blood count, serum electrolytes and thyroid function should be monitored annually. ${ }^{17,152}$

The serial measurement of natriuretic peptides (to optimize the therapy in the case of a concurrent situation of chronic heart failure) showed contrasting results. However, it is demonstrated that high levels of natriuretic peptides are associated with worse prognosis, instead their reduction is associated with a better prognosis. ${ }^{6,153}$

Resting electrocardiogram should be performed annually, even in stable patients. A supplementary electrocardiogram should be performed in case of anginal symptoms modification, onset of syncope or pre-syncope or symptoms compatible with arrhythmias, assumption of new drugs with possible secondary abnormalities of electrical conduction. ${ }^{6}$

Echocardiography should be considered only in case of clinical suspicion: onset or worsening of heart failure or valve disease, evidence of new ischemia. ${ }^{17,152}$ The American Guidelines do not suggest a periodic echocardiographic evaluation in case of stable disease or in low risk patients. ${ }^{17}$

Stress testing is appropriate in the presence of new or worsening symptoms, once unstable angina or acute coronary syndrome have been excluded. The recommendations are similar to the ones used for the diagnosis of suspected IHD. Therefore, a candidate to treadmill stress testing should have an interpretable resting ECG. If resting ECG is uninterpretable or shows LBBB, a stress echocardiography, or a myocardial scintigraphy or, as a second choice, a cardiac MRI should be performed. These same exams should be 
considered as first choice in the event of high risk patient or known multi-vessel diseases. ${ }^{17}$ CCTA could be considered in patients with previous CABG or previous placement of stents $>3 \mathrm{~mm}$ in order to assess their patency, in the context of absence of severe calcifications. ${ }^{17}$

The international guidelines highlight the utility to perform the same test in the same patients to avoid test-dependant discrepancies.

The appropriateness of performing non-invasive testing in patients who are asymptomatic or have stable symptoms depends on factors related to the likelihood of significant findings. There is no current data demonstrating that a follow-up strategy based on the use of stress tests in patients persistently asymptomatic, would improve their outcomes. ${ }^{154,155}$

\section{The management of patient with stable ischemic heart disease}

\section{Rationale and objective}

IHD is a frequent and disabling disease, associated with an appreciable incidence of acute coronary events and increased mortality. For this reason, Internist should know how to treat these patients at best, referring only a small part of them to Cardiologists. It is necessary a great effort because therapy and invasive treatments are continuously progressing and Clinicians should be constantly updated. Therefore, the goal of this work is to raise awareness of the clinical management of stable IHD through a better knowledge of the most recent revisions and guidelines. Some particular aspects will be omitted because they are considered too specialistic and are already outlined in the previous part of this monography.

\section{Methodology}

In order to provide evidence-based recommendations for the management of patients with stable IHD, we first verified the existence of guidelines on the matter. Therefore, we conducted a search using the following database-guidelines: i) Scottish Intercollegiate Guidelines Network (SIGN); ii) Institute for Clinical Systematic Improvement (ICSI); iii) National Institute for Health and Clinical Excellence (NICE) National Health System (NHS) evidence; iv) National Guideline Clearinghouse (NGC); v) Canadian Medical Association, CMA Infobase; vi) New Zealand Guidelines Group; vii) Italian National Health System Guidelines; viii) Clinical Practice Guidelines Portal; ix) eGuidelines.

The research was carried out by seven authors independently, using the terms stable, ischemic, heart, disease as key words, when the site included the search function, and in other cases we listed the last manually guidelines stored in the database. The results obtained separately were then compared and discussed together. The guidelines thus obtained were evaluated using the AGREE instrument ${ }^{156}$ (Appraisal of Guidelines, Research and Evaluation II, 22) by 4 authors independently. AGREE II assesses compliance with 23 requirements, meeting 6 domains as the explanation of the purpose, the clarity, the involvement of all stakeholders, the rigor of development, applicability and editorial independence of the same. Each author assessed the compliance of individual requirements with a score from 1 (disagree completely) to 7 (complete agreement). The scores assigned by each author were added within individual domains and reported with the highest and the lowest score possible within the domain based on the number of requirements included and the number of evaluators.

\section{Results}

Through the databases listed above, we identified 4 guidelines which we evaluated with AGREE method (Table 3). Other references were excluded because too specific and non-functional for our work. By using AGREE criteria we judge the NICE guidelines ${ }^{157}$ on stable IHD to be the best.

Actually, it contains excellent description of target population, objectives and purpose, it does not forget to consider target-population preferences. It emphasizes the role of informed decisions on risks and benefits of different treatments. Further it underlines cultural lacks, unresolved questions of management and it always suggests adequate trials to resolve the uncertainties. It is a complete guideline elaborated in 468 pages; however, there is a shorter version, suitable for clinicians.

$\mathrm{ESC}^{6}$ and $\mathrm{AHA}^{17}$ guidelines are both good guidelines. ESC guidelines contain clear messages, elaborated with many tables and easy to access. However, there is not a precise description of the target population, there are not any considerations about possible barriers to guidelines implementation. Further, the

Table 3. Evaluation of the guidelines on sepsis using the Appraisal of Guidelines, Research and Evaluation II (AGREE) method.

\begin{tabular}{lc}
\hline Guideline & AGREE evaluation \\
\hline $\begin{array}{l}\text { National Institute for Health } \\
\text { and Clinical Excellence (NICE) }\end{array}$ & $81 \%$ \\
\hline European Society of Cardiology (ESC) & $57 \%$ \\
\hline American Heart Association (AHA) & $57 \%$ \\
\hline Canadian Cardiovascular Society (CCS) & $43 \%$ \\
\hline
\end{tabular}


economic aspects are marginally described. AHA is schematic and easy to assess, but it lacks some important aspects: the process used to produce recommendation is not described, time and methods of guideline update are ignored, the barriers to guideline implementation are not considered.

Canadian Cardiovascular Society (CCS) Guidelines ${ }^{4}$ are really synthetic and clear, but there are modest indications on the most recent non-invasive test such as MR and PET. They discuss marginally different revascularization approaches without considering cost, risk and benefits. Barriers to guidelines implementation are not mentioned; a precise description of the target population is absent.

\section{The importance of a correct clinical overview}

Management of stable angina needs great competence and optimal clinical ability since the beginning. Actually, the most important approach is based on a correct clinical overview, starting from symptoms reported analyses. Capacity of distinguishing typical from atypical syndrome is the first necessary step required. ${ }^{4}$ Indeed, risk factors (particularly age and gender) and symptoms permit to stratify pre-test probability of disease. ${ }^{4,6}$ According to this result clinician can suggest to perform nothing or angiography or a non-invasive test to demonstrate clinical suspect of angina. ECG exercise has not a great sensibility and is not advisable when pre-test probability is over $65 \%$. Further, it should not be used in case of LVEF $<50 \%$, exercise limited by orthopedic or other non-cardiac problems or equivocal ECG, such as LBBB, WPW or paced rhythm. ${ }^{6,24}$ Obviously biochemical examination and echocardiography are two precious tests which can facilitate the clinician's approach. Actually, in case of systolic dysfunction it is mandatory to know coronary anatomy and coronary angiography is preferred to CCTA when patient suffers from a typical chest pain. ${ }^{6}$ Troponin, if correctly used, can be helpful to clinician to distinguish acute coronary syndrome. In this case patient management and treatment are based on NSTEMI guidelines ${ }^{6}$ (Figure 2).

\section{Main tests at first medical examination and during follow-up}

Every patient with a diagnosis of stable angina should assess thyroid and kidney function, lipid profile, glycemia and blood count to limit disease progression (controlling risk factors) and ischemia triggers (anemia, hyperthyroidism). ${ }^{6-17}$ These exams should be repeated at least every year during follow$\operatorname{up}^{4,17,152}$ (Table 4).

ECG should be repeated every year and in case of anginal symptoms modification, onset of syncope or pre-syncope or symptoms compatible with arrhythmias, assumption of new drugs with possible secondary abnormalities of electrical conduction. ${ }^{6}$ If nothing emerges from basal ECG, stress test should be performed to investigate potential progression of coronary artery disease or possible stent or graft stenosis.

During follow-up echocardiography should be considered only in case of clinical suspicion: onset or worsening of heart failure or valve disease, evidence of new ischemia. ${ }^{17,152}$

Stress test are useful to demonstrate a suspected clinical diagnosis of angina and to stratify severity. ${ }^{6,158}$ Stress ECG and echocardiography are the most used for their simplicity, low cost and wide-spread availability, whereas stress MR and scintigraphy are not so available outside of academic practice settings. ${ }^{158}$ However MR is recommended in patients in whom, despite the use of echo contrast agents, transthoracic echocardiography cannot be reliable for restricted acoustic window. ${ }^{6}$ When choosing the most appropriate test for a specific patient, clinician should consider patient characteristics, potential contraindications to testing, limitations of each modality, local availability and local expertise. ${ }^{4}$

Angiography is useful in case of symptomatic patients in optimal medical therapy to evaluate the possibility of a revascularization therapy. It can be performed in asymptomatic patients with suspected three vessels or left main coronary anatomy, ${ }^{157}$ because medical treatment is inferior to invasive revascularization such as CABG in this setting. Another debatable indication is represented by high-risk pa-

Table 4. Main tests in stable ischemic heart disease.

\begin{tabular}{lll}
\hline Test & Utility & Indication \\
\hline Blood exams & Control disease progression and ischemia triggers & Every patient, every year \\
\hline ECG & Discover ischemic signs and prognosis & Every patient, every year \\
\hline Echocardiography & Exclude other cardiopathy and evaluate ejection fraction & Every patient \\
\hline Stress test & Diagnosis and stratification & When PTP is $<85 \%$ or follow-up of high risk patients \\
\hline Angiography & Revascularization or anatomy investigation & Uncontrolled symptoms or possible complex lesions \\
& & or high risk patients
\end{tabular}

ECG, electrocardiogram; PTP, termed pre-probability. 


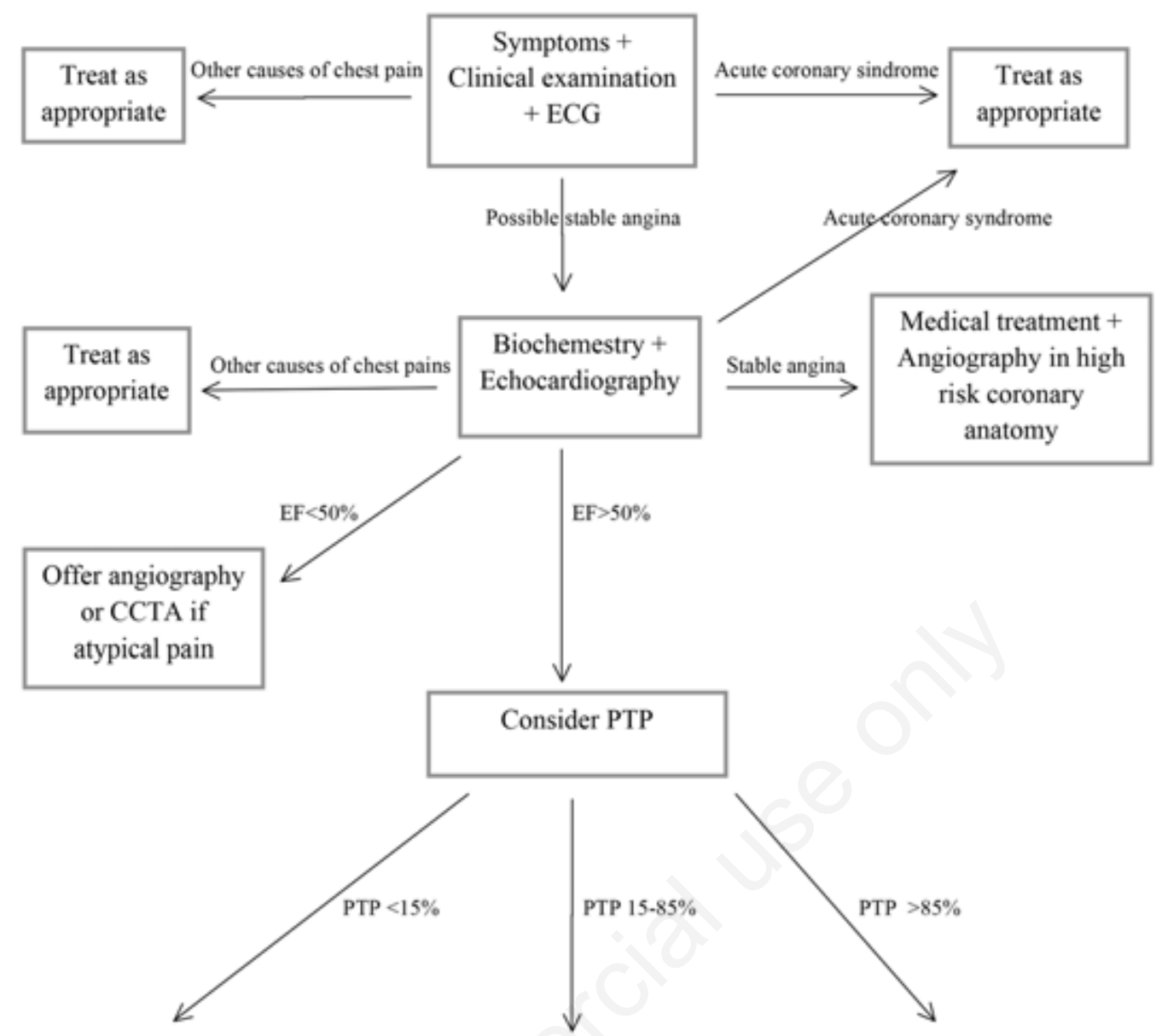

Nothing

Non-invasive test

Angiography


Exercise ECG

Imaging test

Figure 2. Correct management of chest pain. ECG, electrocardiogram; EF, ejection fraction; CCTA, coronary computed tomography angiography; PTP, termed pre-probability.

Table 5. Stratification of risk outcome.

Non-invasive test

Exercise Treadmill

Myocardial perfusion imaging

Stress echocardiography

Coronary computed tomographic angiography
High-risk outcome

$>2 \mathrm{~mm}$ of ST depression at low workload

Exercise-induced ST elevation

Exercise-induced ventricular tachycardia/fibrillation

Failure to increase blood pressure $>120 \mathrm{mmHg}$ or sustained decrease $>10$ $\mathrm{mmHg}$ during exercise

Resting perfusion abnormalities $>10 \%$ of the myocardium

Stress-induced perfusion abnormalities $>10 \%$ of the myocardium or indicating multiple coronary obstruction

Severe stress-induced left ventricular dysfunction

Inducible kinetic abnormalities involving $>2$ coronary beds Kinetic abnormalities developing at low dose of dobutamine

Multi-vessel or left main stenosis 
tients and this common practice is under investigation. ${ }^{158} \mathrm{LVEF}$, ischemic and anatomic burden are the fundamental triad which offers prognostic stratification of patient with stable IHD ${ }^{4}$ (Table 5).

\section{Optimal medical therapy}

Lifestyle modifications and risk factors control are essential aspects to emphasize. ${ }^{6}$ Further therapy is based on anti-anginal drugs and drugs for secondary prevention of cardiovascular disease. ${ }^{43,44}$ The former treatment is based on decreasing oxygen consumption: $\beta$-blockers and calcium channel blockers represent the main stems. ${ }^{6,157}$ Clinicians should choose treatment according to contraindication or patient preference. $\beta$ blockers are preferable in case myocardial infarct history, because these drugs demonstrated a favorable effect on mortality. ${ }^{159}$

Long acting nitrates, ranolazine, ivabradine, nicorandil are possible second line alternative treatments whenever first line treatments are contraindicated or are not tolerated. ${ }^{6}$ Comorbidities, contraindications, person's preference and drug costs are the elements to evaluate for appropriate drug prescription. A triple anti-anginal therapy should be considered only in patients complaining persisting symptoms and presenting non-revascularizable CHD. ${ }^{157}$

Secondary cardiovascular prevention aims to reduce long-term risk of cardiovascular events. Statins and low dose of aspirin should be prescribed to every patient with stable coronary artery disease, after having considered allergies, intolerance and risk of bleeding. ${ }^{6,63-65}$ Aspirin reduces myocardial infarct incidence but not fatal events. At the same time its use is associated with an increased risk of bleeding. ${ }^{160,161}$ For these reasons this treatment should be introduced after having considered bleeding risk and comorbidity. ACEinhibitors are not routinary prescribed in patients with stable coronary artery disease ${ }^{67}$ because their advantages are limited to other settings such as heart failure, hypertension and myocardial infarction.

\section{Medical treatment or invasive approach?}

A clear and undebatable indication for an invasive approach is persisting symptoms in optimal ther-

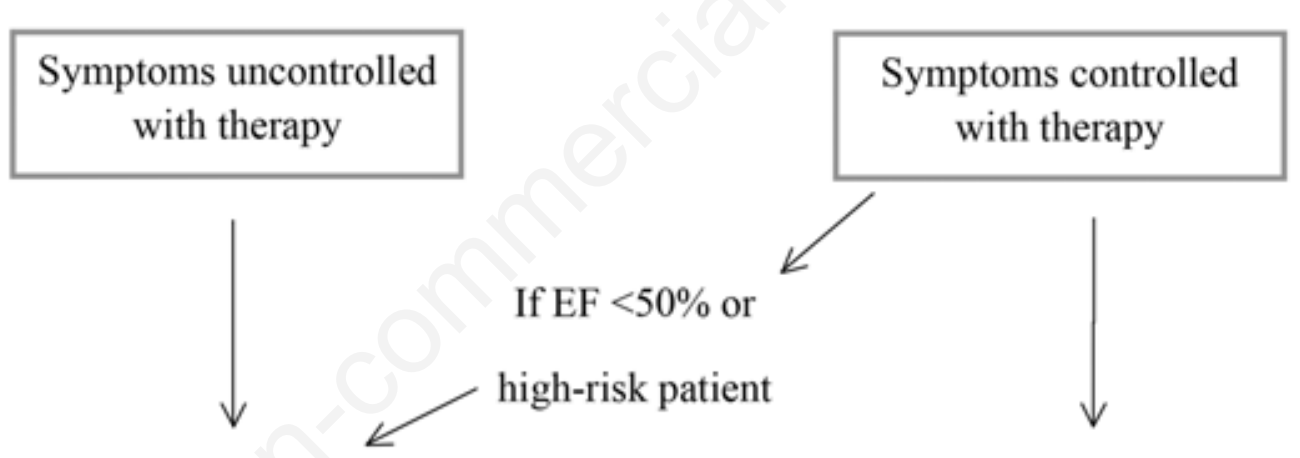

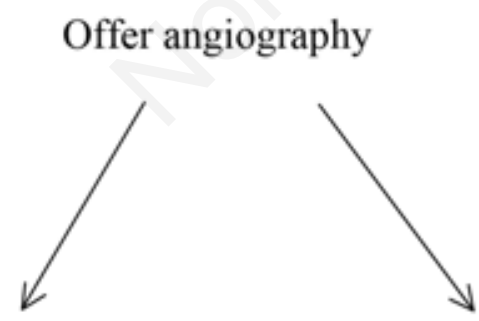

PCI in case of less complex lesions
CABG in case of complex

lesions, left main o 3 vessels
Discuss with patient the possibility

of 3 vessels or left main<smiles>[AlH2]=[V]</smiles>

\section{Angiography}

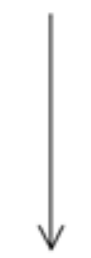

CABG

Figure 3. Angiography indications. EF, ejection fraction; PCI, percutaneous coronary intervention; CABG, coronary artery by-pass grafting. 
apy ${ }^{4,6,17,157}$ (Figure 3 ). Actually coronary artery revascularization with either CABG or PCI should be performed in symptomatic patients, uncontrolled with optimal medical therapy or in case revascularization could improve survival (left main coronary artery disease; three vessel disease, coronary artery disease, particularly with a reduced left ventricular ejection fraction (usually $<40$ percent); or two vessel disease with more than a 75 percent stenosis in the left anterior descending artery proximal to the first major septal artery). ${ }^{102-108}$ However this last indication is based on randomized trials of CABG versus medical treatment that were carried out over 30 years ago, when statins and renin-angiotensin system inhibitors were not available.

If revascularization is desirable, clinician should consider risks and benefits of CABG and PCI, severity and complexity of the person's coronary disease and other relevant clinical factors and comorbidities. ${ }^{157}$ A multidisciplinary team should explain various options to the patient and take account of his preference.

If the patient has anatomically less complex coronary disease and does not express a preference, clinicians should take account of the evidence that PCI may be a more cost-effective procedure. For patients with anatomically complex three-vessel disease, with or without involvement of the left main stem, and for people with multi-vessel disease who have diabetes or are aged $>65$ years, clinicians should take account of the potential survival advantage of CABG over PCI when advising patients about the appropriate revascularization strategy. ${ }^{162}$

\section{References}

1. Kones R, Rumana U. Stable ischemic heart disease. Cardiol Clin 2014;32:333-51.

2. Valgimigli M, Biscaglia S. Stable angina pectoris. Curr Atheroscler Rep 2014;16:422.

3. Crea F, Pupita G, Galassi AR, et al. Role of adenosine in pathogenesis of anginal pain. Circulation 1990;81:164-72.

4. Mancini GB, Gosselin G, Chow B, et al. Canadian Cardiovascular Society guidelines for the diagnosis and management of stable ischemic heart disease. Can J Cardiol 2014;30:837-49.

5. Wilson JF. In the clinic, stable ischemic heart disease. Ann Intern Med 2014;160:1-16.

6. Montalescot G, Sechtem U, Achenbach S. ESC guidelines on the management of stable coronary artery disease. Eur Heart J 2013;34:2949-3003.

7. Information Centre for Health and Social Care. Health Survey for England. Cardiovascular Disease and Risk Factors in Adults. Vol. 1. London: HMSO; 2008.

8. Boden WE, O'Rourke RA, Teo KK, et al. Optimal medical therapy with or without PCI for stablecoronary disease. N Eng J Med 2007;356:1503-16.

9. Chung SC, Hlatky MA, Faxon D, et al. The effect of age on clinical outcomes and health status BARI 2D (Bypass Angioplasty Revascularization Investigation in Type 2 Diabetes). J Am Coll Cardiol 2011;58:810-9.

10. Frye RL, August P, Brooks MM, et al. A randomized trial of therapies for type 2 diabetes and coronary artery disease. N Eng J Med 2009;360:2503-15.

11. Henderson RA, Pocock SJ, Clayton TC, et al. Sevenyear outcome in the RITA-2 trial: coronary angioplasty versus medical therapy. J Am Coll Cardiol 2003;42: 1161-70.

12. Poole-Wilson PA, Lubsen J, Kirwan BA, et al. Effect of long-acting nifedipine on mortality and cardiovascular morbidity in patients with stable angina requiring treatment (ACTION trial): randomised controlled trial. Lancet 2004;364:849-57.

13. Steg PG, Greenlaw N, Tardif JC, et al. Women and men with stable coronary artery disease have similar clinical outcomes: insights from the international prospective CLARIFY registry. Eur Heart J 2012;33:2831-840.

14. Diamond GA. A clinically relevant classification of chest discomfort. J Am Coll Cardiol 1983;1:574-5.

15. Diamond GA, Forrester JS. Analysis of probability as an aid in the clinical diagnosis of coronary-artery disease. N Eng J Med 1979;300:1350-8.

16. Genders TS, Meijboom WB, Meijs MF. CT coronary angiografy in patients suspected of having coronary artery disease: decision making from various perspective in the face of uncertainty. Radiology 2009;253:734-44.

17. Fihn SD, Gardin JM, Abrams J, et al. ACCF/AHA/ ACP/AATS/PCNA/SCAI/STS Guideline for the diagnosis and management of patients with stable ischemic heart disease. J Am Coll Cardiol 2012;60:e44-e164.

18. Zethelius B, Johnston N, Venge P. Troponin I as a predictor of coronary heart disease and mortality in 70year-old men: a community-based cohort study. Circulation 2006;113:1071-8.

19. Omland T, De Lemos JA, Sabatine MS, et al. A sensitive cardiac troponin $\mathrm{T}$ assay in stable coronary artery disease. N Eng J Med 2009;361:2538-47.

20. Ndrepepa G, Braun S, Mehilli J, et al. Prognostic value of sensitive troponin $\mathrm{T}$ in patients with stable and unstable angina and undetectable conventional troponin. Am Heart J 2011;161:68-75.

21. Oremus M, Raina PS, Santaguida P, et al. A systematic review of BNP as a predictor of prognosis in persons with coronary artery disease. Clin Biochem 2008;41: 260-5.

22. Buckley DI, Fu R, Freeman M, et al. C-reactive protein as a risk factor for coronary heart disease: a systematic review and meta-analyses for the U.S. Preventive Services Task Force. Ann Intern Med 2009;151:483-95.

23. Lee TH, Cook EF, Weisberg MC, et al. Impact of the availability of a prior electrocardiogram on the triage of the patient with acute chest pain. J Gen Intern Med 1990;5:381-8.

24. Fox K, Garcia MA, Ardissino D, et al. Guidelines on the management of stable angina pectoris: executive summary The Task Force on the Management of Stable Angina Pectoris of the European Society of Cardiology. Eur Heart J 2006;27:1341-81.

25. Cesar LA, Ferreira JF, Armaganijan D, et al. Guideline for stable coronary artery disease. Arq Bras Cardiol 2014;103:1-56. 
26. Pino GP, Baldini U, Borrello F, Terranova A. Cardiopatia ischemica cronica, cap. 28. Linee Guida SIEC; 2011. Available from: https://www.siec.it/linee-guida/

27. Skinner JS, Smeeth L, Kendall JM, et al. NICE guidance. Chest pain of recent onset: assessment and diagnosis of recent onset chest pain or discomfort of suspected cardiac origin. Heart 2010;96:974-8.

28. Montalescot G, Sechtem U, Achenbach S, et al. 2013 ESC guidelines on the management of stable coronary artery disease - addenda. ESC Guidelines - addenda; available from: www.escardio.org/guidelines

29. Fihn SD, Blankenship JC, Alexander KP, et al. 2014 ACC/AHA/AATS/PCNA/SCAI/STS focused update of the guideline for the diagnosis and management of patients with stable ischemic heart disease: a report of the American College of Cardiology/American Heart Association Task Force on Practice Guidelines, and the American Association for Thoracic Surgery, Preventive Cardiovascular Nurses Association, Society for Cardiovascular Angiography and Interventions, and Society of Thoracic Surgeons. Circulation 2014;130:1749-67.

30. Bruder O, Wagner A, Lombardi M, et al. European cardiovascular magnetic resonance (EuroCMR) registry multi national results from 57 centers in 15 countries. J Cardiovasc Magnet Reson 2013;15:9.

31. Hendel RC, Patel MR, Kramer CM, et al. ACCF/ACR/ SCCT/SCMR/ASNC/NASCI/SCAI/SIR 2006 appropriateness criteria for cardiac computed tomography and cardiac magnetic resonance imaging: a report of the American College of Cardiology Foundation Quality Strategic Directions Committee Appropriateness CriteriaWorking Group, American College of Radiology, Society of Cardiovascular Computed Tomography, Society for Cardiovascular Magnetic Resonance, American Society of Nuclear Cardiology, North American Society for Cardiac Imaging, Society for Cardiovascular Angiography and Interventions, and Society of Interventional Radiology. J Am Coll Cardiol 2006;48:1475-97.

32. Mark DB, Shaw L, Harrell FE Jr, et al. Prognostic value of a treadmill exercise score in outpatients with suspected coronary artery disease. N Engl J Med 1991; 325:849-53.

33. Mark DB, Hlatky MA, Harrell FE Jr, et al. Exercise treadmill score for predicting prognosis in coronary artery disease. Ann Intern Med 1987;106:793-800.

34. Gianrossi R, Detrano R, Mulvihill D, et al. Exercise-induced ST depression in the diagnosis of coronary artery disease. A meta-analysis. Circulation 1989;80:87-98.

35. Kwok Y, Kim C, Grady D, et al. Meta-analysis of exercise testing to detect coronary artery disease in women. Am J Cardiol 1999;83:660-6.

36. Gibson SR. The diagnostic and prognostic value of exercise electrocardiography in asymptomatic subjects and stable symptomatic patients. Curr Opin Cardiol 1991;6: 536-46.

37. Ashley EA, Myers J, Froelicher V. Exercise testing in clinical medicine. Lancet 2000;356:1592-7.

38. Brindis RG, Douglas PS, Hendel RC, et al. ACCF/ ASNC appropriateness criteria for single-photon emission computed tomography myocardial perfusion imaging (SPECT MPI): a report of the American College of Cardiology Foundation Strategic Directions Committee Appropriateness Criteria Working Group and the Amer- ican Society of Nuclear Cardiology. J Am Coll Cardiol 2005; 46:1587-605.

39. Schwitter J, Wacker CM, van Rossum AC, et al. MRIMPACT: comparison of perfusion-cardiac magnetic resonance with single photon emission computed tomography for the detection of coronary artery disease in a multicentre, multivendor, randomized trial. Eur Heart J 2008;29:480-9.

40. Nandalur KR, Dwamena BA, Choudhri AF, et al. Diagnostic performance of positron emission tomography in the detection of coronary artery disease: a meta-analysis. Acad Radiol 2008;15:444-51.

41. Gibbons RJ, Abrams J, Chatterjee K, et al. ACC/AHA 2002 Guideline update for the management of patients with chronic stable angina. Circulation 2003;107: 149-58.

42. Abrams J, Thadani U. Therapy of stable angina pectoris: the uncomplicated patient. Circulation 2005;112:e255-9.

43. Fihn SD, Gardin JM, Abrams J, et al. 2012 ACCF/AHA/ ACP/AATS/PCNA/SCAI/STS guideline for the diagnosis and management of patients with stable ischemic heart disease: a report of the American College of Cardiology Foundation/American Heart Association task force on practice guidelines, and the American College of Physicians, American Association for Thoracic Surgery, Preventive Cardiovascular Nurses Association, Society for Cardiovascular Angiography and Interventions, and Society of Thoracic Surgeons. Circulation 2012;126 :e354-471.

44. Winniford MD, Wheelan KR, Kremers MS, et al. Smoking-induced coronary vasoconstriction in patients with atherosclerotic coronary artery disease: evidence for adrenergically mediated alterations in coronary artery tone. Circulation 1986;73:662-67.

45. Bangalore S, Steg G, Deedwania P, et al. $\beta$-Blocker use and clinical outcomes in stable outpatients with and without coronary artery disease. JAMA 2012;308:1340-9.

46. Andersson C, Shilane D, Go AS, et al. $\beta$-blocker therapy and cardiac events among patients with newly diagnosed coronary heart disease. J Am Coll Cardiol 2014;64:247-52.

47. Braunwald E. Mechanism of action of calcium-channelblocking agents. N Engl J Med 1982;307:1618-27.

48. Emanuelsson H, Egstrup K, Nikus K, et al. Antianginal efficacy of the combination of felodipine-metoprolol $10 / 100 \mathrm{mg}$ compared with each drug alone in patients with stable effort-induced angina pectoris: a multicenter parallel group study. The TRAFFIC Study Group. Am Heart J 1999;137:854-62.

49. Thadani U, Fung HL, Darke AC, et al. Oral isosorbide dinitrate in angina pectoris: comparison of duration of action an dose-response relation during acute and sustained therapy. Am J Cardiol 1982;49:411-9.

50. Henderson RA, O'Flynn N. Management of stable angina: summary of NICE guidance. Heart 2012; 98:500-7.

51. Parker JO. Eccentric dosing with isosorbide-5-mononitrate in angina pectoris. Am J Cardiol 1993;72:871-6.

52. Chaitman BR. Ranolazine for the treatment of chronic angina and potential use in other cardiovascular conditions. Circulation 2006;113:2462-72.

53. Morrow DA, Scirica BM, Karwatowska-Prokopczuk E, et al. Effects of ranolazine on recurrent cardiovascular 
events in patients with non-ST-elevation acute coronary syndromes: the MERLIN-TIMI 36 randomized trial. JAMA 2007;297:1775-83.

54. Morrow DA, Scirica BM, Chaitman BR, et al. Evaluation of the glycometabolic effects of ranolazine in patients with and without diabetes mellitus in the MERLIN-TIMI 36 randomized controlled trial. Circulation 2009;119:2032-9.

55. Kosiborod M, Arnold SV, Spertus JA, et al. Evaluation of Ranolazine in Patients with Type 2 Diabetes Mellitus and Chronic Stable Angina. Results from the TERISA randomized clinical trial. J Am Coll Cardiol 2013;61:2038-45.

56. Chaitman BR, Skettino SL, Parker JO, et al. Antiischemic effects and long-term survival during ranolazine monotherapy in patients with chronic severe angina. J Am Coll Cardiol 2004;43:1375-82.

57. Chaitman BR, Pepine CJ, Parker JO, et al. Effects of ranolazine with atenolol, amlodipine, or diltiazem on exercise tolerance and angina frequency in patients with severe chronic angina: a randomized controlled trial. JAMA 2004;291:309-16.

58. Rousseau MF, Pouleur H, Cocco G, et al. Comparative efficacy of ranolazine versus atenolol for chronic angina pectoris. Am J Cardiol 2005;95:311-6.

59. Stone PH, Gratsiansky NA, Blokhin A, et al; ERICA Investigators. Antianginal efficacy of ranolazine when added to treatment with amlodipine: the ERICA (Efficacy of Ranolazine in Chronic Angina) trial. J Am Coll Cardiol 2006;48:566-75.

60. Henry TD, Satran D, Hodges JS, et al. Traverse JH. Long-term survival in patients with refractory angina. Eur Heart J 2013;34:2683-8.

61. Thadani U, Ezekowitz M, Fenney L, et al. Double-blind efficacy and safety study of a novel anti-ischemic agent, ranolazine, versus placebo in patients with chronic stable angina pectoris. Circulation 1994;90:726-34.

62. Kosiborod M, Arnold SV, Spertus JA, et al. Evaluation of ranolazine in patients with type 2 diabetes mellitus and chronic stable angina: results from the TERISA randomized clinical trial (type 2 diabetes evaluation of ranolazine in subjects with chronic stable angina). J Am Coll Cardiol 2013;61:2038-45.

63. Koren MJ, Crager MR, Sweeney M. Long-term safety of a novel antianginal agent in patients with severe chronic stable angina: the ranolazine open label experience (ROLE). J Am Coll Cardiol 2007;49:1027-34.

64. Fihn SD, Gardin JM, Abrams J, et al. 2012 ACCF/ AHA/ACP/AATS/PCNA/SCAI/STS guideline for the diagnosis and management of patients with stable ischemic heart disease: a report of the American College of Cardiology Foundation/American Heart Association task force on practice guidelines, and the American College of Physicians, American Association for Thoracic Surgery, Preventive Cardiovascular Nurses Association, Society for Cardiovascular Angiography and Interventions, and Society of Thoracic Surgeons. Circulation 2012;126:354-471.

65. Lopatin YM. Russian Multicenter Observational Program NACHALO. Evaluation of the antianginal efficacy of ivabradine in patients with ischemic heart disease complicated by heart failure. Kardiologiia 2015;55:5-11.
66. Tardif JC, Ford I, Tendera M, et al. Efficacy of ivabradine, a new selective I(f) inhibitor, compared with atenolol in patients with chronic stable angina. Eur Heart J 2005;26:2529-36.

67. Fox K, Ford I, Steg PG, et al. Ivabradine for patients with stable coronary artery disease and left-ventricular systolic dysfunction (BEAUTIFUL): a randomised, double-blind, placebo-controlled trial. Lancet 2008; 372:807-16.

68. Fox K, Ford I, Steg PG, et al. Ivabradine in stable coronary artery disease without clinical heart failure. $\mathrm{N}$ Engl J Med 2014;371:1091-9.

69. Tendera M, Chassany O, Ferrari R, et al. Quality of life with ivabradine in patients with angina pectoris the study assessing the morbidity-mortality benefits of the if inhibitor ivabradine in patients with coronary artery disease quality of life substudy. Circ Cardiovasc Qual Outcomes 2016;9:31-8.

70. Ford I (The IONA Study Group). Effect of nicorandil on coronary events in patients with stable angina: the impact of nicorandil in angina (IONA) randomised trial. Lancet 2002;359:1269-75.

71. Ford I (The IONA Study Group). Impact of nicorandil in angina: subgroup analyses IONA Study Group. Heart 2004;90:1427-30.

72. Carolei A. CAPRIE Steering Committee: A randomised, blinded, trial of clopidogrel versus aspirin in patients at risk of ischaemic events (CAPRIE). Lancet 1996; 348:1329-39.

73. Reiner Z, Catapano AL, De Backer G, et al. ESC/EAS Guidelines for the management of dyslipidaemias: the Task Force for the management of dyslipidaemias of the European Society of Cardiology (ESC) and the European Atherosclerosis Society (EAS). Eur Heart J 2011;32:1769-818.

74. Pitt B, Waters D, Brown WV, et al. Aggressive lipidlowering therapy compared with angioplasty in stable coronary artery disease. Atorvastatin versus Revascularization Treatment Investigators. N Engl J Med 1999; 341:70-6.

75. Deanfield JE, Sellier P, Thaulow E, et al. Potent anti-ischaemic effects of statins in chronic stable angina: incremental benefit beyond lipid lowering? Eur Heart J 2010;31:2650-9.

76. Dagenais GR, Pogue J, Fox K, et al. Angiotensin-converting-enzyme inhibitors in stable vascular disease without left ventricular systolic dysfunction or heart failure: a combined analysis of three trials. Lancet 2006; 368:581-8.

77. Braunwald E, Domanski MJ, Fowler SE, et al. Angiotensin-converting-enzyme inhibition in stable coronary artery disease. N Eng J Med 2004;351:2058-68.

78. Kolh P, Wijns W, Danchin N, et al. Guidelines on myocardial revascularization. Eur J Cardiothorac Surg 2010;38:S1-52.

79. Wijns W, Kolh P, Danchin N, et al. Guidelines on myocardial revascularization: The Task Force on Myocardial Revascularization of the European Society of Cardiology (ESC) and the European Association for Cardio-Thoracic Surgery (EACTS). Eur Heart J 2010;31:2501-55.

80. Deb S, Wijeysundera HC, Ko DT, et al. Coronary artery bypass graft surgery vs.percutaneous interventions in 
coronary revascularization: a systematic review. JAMA 2013;310:2086-95.

81. Head SJ, Kieser TM, Falk V, et al. Coronary artery bypass grafting: Part 1: the evolution over the first 50 years. Eur Heart J 2013;34:2862-72.

82. Gruntzig A. Transluminal dilatation of coronary-artery stenosis. Lancet 1978;1:263.

83. Stefanini GG, Holmes DR Jr. Drug-eluting coronaryartery stents. N Engl J Med 2013;368:254-65.

84. Healthwise Staff. Anticoagulants for heart attack and unstable angina. Last Revised: February 13, 2013. Available from: http://www.wakemed.org/body.cfm?id=4616 \&action=detail\&AEProductID $=$ HW_Knowledgebase $\& A E A r t i c l e I D=t x 4242$

85. Head SJ, Kaul S, Mack MJ, et al. The rationale for Heart Team decision-making for patients with stable, complex coronary artery disease. Eur Heart J 2013;34:2510-8.

86. Head SJ, Holmes DR Jr., Mack MJ, et al. Investigators S. Risk profile and 3-year outcomes from the SYNTAX percutaneous coronary intervention and coronary artery bypass grafting nested registries. JACC Cardiovasc Interv 2012;5:618-25.

87. Nashef SA, Roques F, Michel P, et al. European system for cardiac operative risk evaluation (EuroSCORE). Eur J Cardiothorac Surg 1999;16:9-13.

88. Nashef SA, Roques F, Sharples LD, et al. EuroSCORE II. Eur J Cardiothorac Surg 2012;41:734-44; discussion 744-5.

89. Biancari F, Vasques F, Mikkola R, et al. Validation of Euro SCORE II in patients undergoing coronary artery bypass surgery. Ann Thorac Surg 2012;93:1930-5.

90. Shahian DM, O'Brien SM, Filardo G, et al. Society of Thoracic Surgeons Quality Measurement Task F. The Society of Thoracic Surgeons 2008 cardiac surgery risk models: part 3: valve plus coronary artery bypass grafting surgery. Ann Thorac Surg 2009;88:S43-62.

91. Mohr FW, Morice MC, Kappetein AP, et al. Coronary artery bypass graft surgery vs. percutaneous coronary intervention in patients with three-vessel disease and left main coronary disease: 5-year follow-up of the randomised, clinical SYNTAX trial. Lancet 2013;381:629-38.

92. Peterson ED, Dai D, DeLong ER, et al. Contemporary mortality risk prediction for percutaneous coronary intervention: results from 588,398 procedures in the $\mathrm{Na}$ tional Cardiovascular Data Registry. J Am Coll Cardiol 2010;55:1923-32.

93. Wykrzykowska JJ, Garg S, Onuma Y, et al. Value of age, creatinine, and ejection fraction (ACEF score) in assessing risk in patients undergoing percutaneous coronary interventions in the 'All-Comers' LEADERS trial. Circ Cardiovasc Interv 2011;4:47-56.

94. Farooq V, van Klaveren D, Steyerberg EW, et al. Anatomical and clinical characteristics to guide decision making between coronary artery bypass surgery and percutaneous coronary intervention for individual patients: development and validation of SYNTAX score II. Lancet 2013;381:639-50.

95. Weintraub WS, Grau-Sepulveda MV, Weiss JM, et al. Comparative effectiveness of revascularization strategies. N Engl J Med 2012;366:1467-76.

96. Shahian DM, O'Brien SM, Sheng S, et al. Predictors of long-term survival after coronary artery bypass grafting surgery: results from the Society of Thoracic Surgeons
Adult Cardiac Surgery Database (the ASCERT study). Circulation 2012;125:1491-500.

97. Weintraub WS, Grau-Sepulveda MV, Weiss JM, et al. Prediction of long-term mortality after percutaneous coronary intervention in older adults: results from the National Cardiovascular Data Registry. Circulation 2012;125:1501-10.

98. Windecker S, Kolh P, Alfonso F, et al. 2014 ESC/EACTS Guidelines on myocardial Revascularization. The Task Force on Myocardial Revascularization of the European Society of Cardiology (ESC) and the European Association for Cardio-Thoracic Surgery (EACTS). European Heart Journal web addenda; available from: https://www.escardio.org/static_file/Escardio/Guidelines/publications/PCIMR-Web\%20addenda.pdf

99. Boden WE, O'Rourke RA, Teo KK et al. Optimal medical therapy with or without PCI for stable coronary disease. N Engl J Med 2007;356:1503-16.

100. Bucher HC, Hengstler P, Schindler C, et al. Percutaneous transluminal coronary angioplasty vs. medical treatment for non-acute coronary heart disease: metaanalysis of randomised controlled trials. BMJ 2000;32: 73-7.

101. Katritsis DG, Ioannidis JP. Percutaneous coronary intervention vs. conservative therapy in nonacute coronary artery disease: a meta-analysis. Circulation 2005; 111:2906-12.

102. Stergiopoulos K, Brown DL. Initial coronary stent implantation with medical therapy vs.medical therapy alone for stable coronary artery disease: meta-analysis of randomized controlled trials. Arch Intern Med 2012;172:312-9.

103. Bangalore S, Kumar S, Fusaro M et al. Short- and longterm outcomes with drug-eluting and bare-metal coronary stents: a mixed-treatment comparison analysis of 117,762 patient-years of follow-up from randomized trials. Circulation 2012;125:2873-91.

104. Stettler C, Wandel S, Allemann S, et al. Outcomes associated with drug-eluting and bare-metal stents: a collaborative network meta-analysis. Lancet 2007;370: 937-48.

105. Stefanini GG, Byrne RA, Serruys PW, et al. Biodegradable polymer drug-eluting stents reduce the risk of stent thrombosis at 4 years in patients undergoing percutaneous coronary intervention: a pooled analysis of individual patient data from the ISAR-TEST 3, ISAR-TEST 4, and LEADERS randomized trials. Eur Heart J 2012;33:1214-22.

106. Stefanini GG, Baber U, Windecker S, et al. Safety and efficacy of drug-eluting stents in women: a patient-level pooled analysis of randomized trials. Lancet 2013;382:1879-88.

107. Stefanini GG, Kalesan B, Serruys PW, et al. Long-term clinical outcomes of biodegradable polymer biolimuseluting stents vs. durable polymer sirolimus-eluting stents in patients with coronary artery disease (LEADERS): 4 year follow-up of a randomised non-inferiority trial. Lancet 2011;378:1940-8.

108. Palmerini T, Biondi-Zoccai G, Della Riva D, et al. Stent thrombosis with drug-eluting and bare-metal stents: evidence from a comprehensive network meta-analysis. Lancet 2012;379:1393-402.

109. Yusuf S, Zucker D, Peduzzi P, et al. Effect of coronary 
artery bypass graft surgery on survival: overview of 10 year results from randomised trials by the Coronary Artery Bypass Graft Surgery Trialists Collaboration. Lancet 1994;344:563-70.

110. Jeremias A, Kaul S, Rosengart TK, et al. The impact of revascularization on mortality in patients with nonacute coronary artery disease. Am J Med 2009;122:152-61.

111. Detre KM, Frye RL, Genuth S. A symposium: treatment of coronary artery disease and type 2 diabetes: the rationale for the bypass angioplasty revascularization investigation 2 diabetes (BARI 2D) trial. Am J Cardiol 2006;97:1G-65G.

112. Kapoor JR, Gienger AL, Ardehali R, et al. Isolated disease of the proximal left anterior descending artery comparing the effectiveness of percutaneous coronary interventions and coronary artery bypass surgery. JACC Cardiovasc Interv 2008;1:483-91.

113. Aziz O, Rao C, Panesar SS, et al. Meta-analysis of minimally invasive internal thoracic artery bypass vs. percutaneous revascularization for isolated lesions of the left anterior descending artery. BMJ 2007;334:617.

114. Morice MC, Serruys PW, Kappetein AP, et al. Outcomes in patients with de novo left main disease treated with either percutaneous coronary intervention using paclitaxel-eluting stents or coronary artery bypass graft treatment in the synergy between percutaneous coronary intervention with TAXUS and cardiac surgery (SYNTAX) trial. Circulation 2010;121: 2645-53.

115. Capodanno D, Stone GW, Morice MC, et al. Percutaneous coronary intervention vs. coronary artery bypass graft surgery in left main coronary artery disease: a meta-analysis of randomized clinical data. J Am Coll Cardiol 2011;58:1426-32.

116. Hlatky MA, Boothroyd DB, Bravata DM, et al. Coronary artery bypass surgery compared with percutaneous coronary interventions for multivessel disease: a collaborative analysis of individual patient data from ten randomised trials. Lancet 2009;373:1190-7.

117. Sipahi I, Akay MH, Dagdelen S, et al. Coronary artery bypass grafting vs percutaneous coronary intervention and long-term mortality and morbidity in multivessel disease: meta-analysis of randomized clinical trials of the arterial grafting and stenting era. JAMA Intern Med 2014;174:223-30.

118. Mehta RH, Lopes RD, Ballotta A, et al. Percutaneous coronary intervention or coronary artery bypass surgery for cardiogenic shock and multivessel coronary artery disease? Am Heart J 2010;159:141-7.

119. Brooks MM, Frye RL, Genuth S, et al. Hypotheses, design and methods for the Bypass Angioplasty Revascularization Investigation 2 (BARI 2D) trial. Am J Cardiol 2006;97:9G-19G

120. Reis SE, Holubkov R, Conrad Smith AJ, et al. Coronary microvascular dysfunction is highly prevalent in women with chest pain in the absence of coronary artery disease: results from the NHLBI WISE study. Am Heart J 2001;141:735.

121. Lanza GA, Giordano A, Pristipino C, et al. Abnormal cardiac adrenergic nerve function in patients with syndrome $\mathrm{X}$ detected by [123I] metaiodobenzylguanidine myocardial scintigraphy. Circulation 1997;96:821.

122. Madaric J, Bartunek J, Verhamme K, et al. Hyperdy- namic myocardial response to beta-adrenergic stimulation in patients with chest pain and normal coronary arteries. J Am Coll Cardiol 2005;46:1270.

123. Cannon RO. The sensitive heart. A syndrome of abnormal cardiac pain perception. JAMA 1995;273:883-7.

124. Fedele F, Agati L, Pugliese M et al. Role of central endogenous opiate system in patients with syndrome X. Am Heart J 1998;136:1003-9.

125. Kaski JC, Rosano GM, Collins P, et al. Cardiac syndrome $\mathrm{X}$ : clinical characteristics and left ventricular function. Long-term follow-up study. J Am Coll Cardiol 1995;25:807.

126. Johnson BD, Shaw LJ, Buchthal SD, et al. Prognosis in women with myocardial ischemia in the absence of obstructive coronary disease: results from the National Institutes of Health-National Heart, Lung, and Blood Institute-Sponsored Women's Ischemia Syndrome Evaluation (WISE). Circulation 2004;109:2993.

127. Germing A, Lindstaedt M, Ulrich S, et al. Normal angiogram in acute coronary syndrome-preangiographic risk stratification, angiographic findings and follow-up. Int J Cardiol 2005;99:19.

128. Bugiardini R, Manfrini O, De Ferrari GM. Unanswered questions for management of acute coronary syndrome: risk stratification of patients with minimal disease or normal findings on coronary angiography. Arch Intern Med 2006;166:1391.

129. Rosen SD, Uren NG, Kaski JC, et al. Coronary vasodilator reserve, pain perception, and sex in patients with syndrome X. Circulation 1994;90:50-60.

130. Eriksson BE, Tyni-LennèR, Svedenhag J, et al. Physical training in syndrome $\mathrm{X}$ : physical training counteracts deconditioning and pain in Syndrome X. J Am Coll Cardiol 2000;36:1619.

131. Kanatsuka H, Eastham CL, Marcus ML, et al. Effects of nitroglycerin on the coronary microcirculation in normal and ischemic myocardium. J Cardiovasc Pharmacol 1992;19:755.

132. Lanza GA, Manzoli A, Pasceri V, et al. Ischemic-like ST-segment changes during Holter monitoring in patients with angina pectoris and normal coronary arteries but negative exercise testing. Am J Cardiol 1997;79:1.

133. Maseri A. Ischemic heart disease. London: Churchill Livingstone; 1995.

134. Fragasso G, Rossetti E, Dosio F, et al. High prevalence of the thallium-201 reverse redistribution phenomenon in patients with syndrome X. Eur Heart J 1996;17:1482.

135. Anselmi M, Golia G, Marino P, et al. Comparison of left ventricular function and volumes during transesophageal atrial pacing combined with two-dimensional echocardiography in patients with syndrome X, atherosclerotic coronary artery disease, and normal subjects. Am J Cardiol 1997; 80:1261.

136. Panting JR, Gatehouse PD, Yang GZ, et al. Abnormal subendocardial perfusion in cardiac syndrome $\mathrm{X}$ detected by cardiovascular magnetic resonance imaging. N Engl J Med 2002;346:1948.

137. Atmaca Y, Ozdemir AO, Ozdol C, et al. Angiographic evaluation of myocardial perfusion in patients with syndrome X. Am J Cardiol 2005;96:803.

138. Reis SE, Holubkov R, Conrad Smith AJ, et al. Coronary microvascular dysfunction in highly prevalent in women with chest pain in the absence of coronary ar- 
tery disease: results from the NHLBI WISE study. Am Heart J 2001;141:735-41.

139. Lee DC, Simonetti OP, Harris KR, et al. Magnetic resonance versus radionuclide pharmacological stress perfusion imaging for flow-limiting stenoses of varying severity. Circulation 2004;110:58-65.

140. Mueller PS, Edwards WD, Gertz MA. Symptomatic ischemic heart disease resulting from obstructive intramural coronary amyloidosis. Am J Med 2000;109:181-8.

141. Sicari R, Palinkas A, Pasanisi EG, et al. Long-term survival of patients with chest pain syndrome and angiographically normal or near-normal coronary arteries: the additional prognostic value of dipyridamole echocardiography test (DET). Eur Heart J 2005;26:2136.

142. Treasure CB, Klein JL, Weintraub WS, et al. Beneficial effects of cholesterol-lowering therapy on the coronary endothelium in patients with coronary artery disease. $\mathrm{N}$ Engl J Med 1995;332:481.

143. Fragasso G, Chierchia SL, Pizzetti G, et al. Impaired left ventricular filling dynamics in patients with angina and angiographically normal coronary arteries: effect of beta adrenergic blockade. Heart 1997;77:32.

144. Mehta PK, Goykhman P, Thomson LE, et al. Ranolazine improves angina in women with evidence of myocardial ischemia but no obstructive coronary artery disease. JACC Cardiovasc Imaging 2011;4:514.

145. Roqué M, Heras M, Roig E, et al. Short-term effects of transdermal estrogen replacement therapy on coronary vascular reactivity in postmenopausal women with angina pectoris and normal results on coronary angiograms. J Am Coll Cardiol 1998;31:139-43.

146. Lanza GA, Sestito A, Sgueglia GA, et al. Effect of spinal cord stimulation on spontaneous and stress-induced angina and 'ischemia-like' ST-segment depression in patients with cardiac syndrome X. Eur Heart J 2005;26:983.

147. Mayer-Berger W, Simic D, Mahmoodzad J, et al. Efficacy of a long-term secondary prevention programme following inpatient cardiovascular rehabilitation on risk and health-related quality of life in a low-education cohort: a randomized controlled study. Eur J Prev Cardiol 2014;21:145-52.

148. Daly CA, De Stavola B, Sendon JLL, et al. Predicting prognosis in stable angina - results from the Euro heart survey of stable angina: prospective observational study. BMJ 2006;332:262-7.

149. Daly C, Norrie J, Murdoch DL, et al. The value of routine non-invasive tests to predict clinical outcome in stable angina. Eur Heart J 2003;24:532-40.
150. Clayton TC, Lubsen J, Pocock SJ, et al. Risk score for predicting death, myocardial infarction, and stroke in patients with stable angina, based on a large randomised trial cohort of patients. BMJ 2005;331:869.

151. Specchia G, Boccanelli A, Cella C, et al. Linee guida sulla cardiopatia ischemica cronica. Documento in collaborazione con associazione cardiologi extraospedalieri. Available from: http://docplayer.it/4257089-Lineeguida-sulla-cardiopatia-ischemica-cronica.html

152. Lettino M, Mazzuero A, Tavazzi L. Cardiopatia ischemica cronica: dalla evidenza scientifica alla pratica clinica. Roma: Verduci Editore; 2008.

153. Porapakkham P, Zimmet H, Billah B, et al. B-type natriuretic peptide-guided heart failure therapy: a metaanalysis. Arch Intern Med 2010;170:507-14.

154. Harb SC, Cook T, Jaber WA, et al. Exercise testing in asymptomatic patients after revascularization: are outcomes altered? Arch Intern Med 2012;172:854-61.

155. Hachamovitch R, Hayes S, Friedman JD, et al. Determinants of risk and its temporal variation in patients with normal stress myocardial perfusion scans: what is the warranty period of a normal scan? J Am Coll Cardiol 2003;41:1329-40.

156. AGREE Next Steps Consortium. The AGREE II Instrument [Electronic version]; 2009. Available from: http://www.agreetrust.org

157. National Institute for Health Care and Excellence (NICE). Stable angina: management. Clinical guideline [CG126] - Published date: July 2011. Available from: https://www.nice.org.uk/guidance/cg126

158. ClinicalTrials.gov. International Study of Comparative Health Effectiveness with Medical and Invasive Approaches (ISCHEMIA). Available from: http://clinicaltrials.gov/ct2/show/NCT01471522?term=ISCHEMIA \&rank $=1$

159. Yusuf S, Wittes J, Friedman L. Overview of results of randomized clinical trials in heart disease. I. Treatments following myocardial infarction. JAMA 1988;260:2088-93.

160. Gori T, Parker JD. Nitrate-induced toxicity and preconditioning: a rationale for reconsidering the use of these drugs. J Am Coll Cardiol 2008;52:251-4.

161. Serebruany VL, Steinhubl SR, Berger PB, et al. Analysis of risk of bleeding complications after different doses of aspirin in 192036 patients enrolled in 31 randomized controlled trials. Am J Cardiol 2005;95:1218-22.

162. Windecker S, Stortecky S, Stefanini GG, et al. Revascularisation versus medical treatment in patients with stable coronary artery disease: network meta-analysis. BMJ 2014;348:g3859. 